\title{
Research on Qi Dian
}

\author{
Shengde Fang \\ Huanggang Normal University \\ Huanggang, China 438000
}

\begin{abstract}
There were records about Qi Dian about one thousand years ago. However, its making material and methods were not clearly recorded in the literature. It hinders the research and development of Qi Dian. The paper is aimed to research its value in the development of history and promote its modern transformation and development. The authors has used the research methods of literature sorting and field investigation to research the making materials and functions of Qi Dian. Finally, it concludes its health care function. Only by putting aside the bound of these researches on Qi Zhu, may Qi Dian get a new development.
\end{abstract}

Keywords-Qi Dian; Qi bamboo; research; development

\section{INTRODUCTION}

"There are four treasures in Qichun, turtle, snake, bamboo and wormwood." It has been a popular folk proverb in Hubei Qichun for generations. There are many records about these four things in Qizhou Records and many ancient books of the Ming and Qing Dynasties. They can be used as medicine which is their common characteristic. Only Qi bamboo can be used to make bamboo products, such as bamboo mat, bamboo flute and bamboo cane and "bamboo wife". Guangqun Fangpu · Bamboo Manual · One recorded: "Qi Bamboo comes from Huangzhou Qizhou. The bright part can be used to make mat; the part near the root can be used to make flute; the part with hair can be used to make cane." Among them, Qi Dian is best known for its exquisite fabrication and portable characteristic. It can be folded and rolled, as household necessities. It has been eulogized by ancient literati.

\section{QI DIAN IN ANCIENT POEMS}

Shuowen said Dian was bamboo mat. Yangzi Localism said Song people called it Sheng and people in Guan xi called it Dian. Poem - Customs of Qi recorded the cart had a bamboo mat curtain and a red hide cover. Xiaoya recorded put tabernaemontanus bulrush mat under bamboo mat. Rites . Sacrificial Vessels recorded people used tabernaemontanus bulrush mat and bamboo mat for sleep and straw mat for sacrifice. Zuosi - Prose of Wu Capital recorded Taozhi ba mboo mat and ivory mat. Kangxi Dictionary explains "Dian" is bamboo mat with square pattern. In the Western Han Dynasty, people in some places called it Sheng. There were also Dian made of ivory, generally put on reed mat to make it more comfortable.

Dian is an important article for ancient people to relieve summer heat. It is difficult for us to imagine that the ancients did not have air conditioning in hot summer. In the nowadays the temperature generally is higher than that in ancient days due to "the greenhouse effect". But it was still hard for ancient people to face hot weather. There are poems as evidence. In Kure Xing, Wang Wei said "it was so hot even using weed mat and bamboo mat, wearing cool clothes and having a bath. In Hot Summer, May 2nd, Yang Wanli said "it was very hot and even the sun could boil water. There was no place to escape summer heat. There was no wind. Sweat poured down like raindrops". Fan Deng said "June is the hottest month. The body is sweaty all day (June). Zhag Lai said "before working, sweat poured down like water" (Song of Labor). Dai Fugu said "the river water seems to be boiled. I sweat like a pig" (Great Heat). Therefore, facing hot summer, Dian became an every essential necessity, especially in hu mid southern regions.

Dian has a unique refreshing function; so many poets have described it in their poems and prose. In these poems and prose, Qi Dian is praised as a local specialty and a precious gift to friends and relatives. For example, Han Yu, in Giving Zheng Qun Dian for Thanks, said "bamboo flute in Qizhou is wellknown. Mr. Zheng treats it like a treasure". Liu Yuxi, in Giving Li Langzhong in Qizhou a Farewell Dinner, wrote "in hot summer, we boiled new tea and gave a bamboo mat to see our friend off". Bai Juyi, in Letter to Li Qizhou, "the sad flute sound disappeared at the end of spring. The cool Dian grows mature in fall". Ou Yangxiu, in To Yuanfu Shengyu Zhijiang, "people in Qizhou made it into double water pattern"; "it looks like yellow glaze and green jade. It is smooth and cool with no dust". Wang Anshi, in Rely to Ouyang Yongshu about Duanxi Stone Pillow and Qizhou Dian, wrote "in Qishui Dian is made into gold pattern". Su Shi, in Sishi $\cdot$ Fall, wrote "all the old and recent grudges made me frown in grief. Qi bamboo mat gave off sweaty stink and power fragrance". Wen Tong, in The Third Letter to Wu Longtu in Yongxing, wrote "there are a few affairs when no guests come. It is so cool to sleep on Qi Dian". Zhou Mi, in Past Stories of Wulin - Escaping Summer Heat, said "if do not feel troublesome, you can set a shed and enjoy the cool on Qi Dian". Lu You, in Thinking in Fall, said "it is cool and wonderful in fall with Qi Dian and Qi flute." Qi Dian was also paid as tribute. Prime Minister Fan Chunren in the Northern Song Dynasty of Zhezong Emperor has mentioned Qi Dian in his two poems. Giving Qi Dian to Lu Gong wrote: "it is rolled like a small coiling block. Put it on bed to make cool in June", and "give the imperial family a good stuff so that they could sleep well". In addition, Qizhou Records in the Qing Dynasty of Kangxi Emperor, Qianlong Emperor, Xianfeng Emperor and Guangxu Emperor have recorded an article of Emperor Gao Taizu Stop at Qizhou and Give Instruction about Dian. It says "all square tributes given by the ancient were for eating, so it had no function of entertainment. Now officials 
offer bamboo mat. It is useful. But if everyone offers tribute with no order, I'm afraid all the officials will strive to give presents. It wastes manpower and money. So, from today on, stop do it. All of you only give necessary goods to the imperial family. Don't pay tributes at will." At the end of Ming Dynasty and the beginning of Qing Dynasty, the litterateur Gu Jing xing, in Qi Bamboo . One described: "if it were not for Qi bamboo, it is of no avail to cut down thous ands of trees in Qiyuan. I ever heard that Emperor Gao looked down upon the square thing, and the officials paid Dian and flute as tributes without order". It explains Qi Dian is possible to be offered as tribute.

\section{THE RESEARCH AND DEVELOPMENT OF QI DIAN IN MODERN TIMES}

Since the Ming Dynasty, there are only a few records about Qi bamboo and Qi Dian. In the Ming Dynasty of Jiajing Emperor, Qizhou Records recorded "mat, made of Long xu, is inferior to mat made of Qiyang bamboo. Qi Dian is as cool as water and as smooth as vine skin. To make a bamboo mat costs for days. If one official ask for it, no one dare to offend him and he only give an order'[1]. In the middle of Ming Dynasty, the seeds of capitalism caused some mat craftsmen transfer to other industries. Thus, the production of Qi Dian reduced. At the end of Ming Dynasty, there is still Qi Dian in the market. "In the February of last year (1987), Dian was unearthed from a tomb of Ming Dynasty, more than 350 years ago, in Qichun Xize. It was as good as new after washing"'[2]. In addition, $\mathrm{Gu}$ Jingxing, main editor of Qizhou Records in the period of Kangxi Emperor and litterateur at the end of Ming Dynasty and at the beginning of Qing Dynasty, wrote "Qi bamboo is able to make color Feng ming. Minyun bamboo mat is superior to Tao Sheng. But now we can seek nothing in the mountain because of destroy of warfare" in the Qi Bamboo ·Four. Another poem said "it is of no avail to cut down all trees". He referred to this historical fact. According to Records of Qichun County (1997), "in the second year of Shunzhi Emperor (1645, Qing Dynasty), Zuo Liangyu killed Ma Shiying and Ruan Dacheng in the name of sweeping away bad men around the emperor. He led 800000 soldiers and started from Wuchang and passed Qizhou to the east. He indulged his soldiers burn crops and plunder people. Fields and gardens were destroyed, and Qi bamboos were chopped down"[3]. According to this record, at the time of Gu Jing xing, Qizhou didn't produce Qi Dian any more. Otherwise, the litterateur couldn't make such a sign.

Another record further shows new features of Qi Dian. Records of Huguang Tujing recorded: "Baijiaye Mountain, located 30 miles away from the northeast of the county, abounded with Qi bamboo" [4]. Qizhou Records in the Qing Dynasty of Guangxu Emperor recorded: "Dian was made of Baijiaye Mountain bamboo. Now there is no bamboo on the mountain, so mat craftsmen use bamboo of other places. But they also call it Qi Dian" [5]. About at this time, the literature and facts confirm that "Qi bamboo has disappeared". However, craftsmen still make Qi Dian. Raw material is changed, but craftsmanship is handed down. Records of Qichun County (1997) recorded: "Craftsman Ye Caihua learned an artistic skill from his father since his childhood. His reputation had been spread in Qichun, Yingshan, Xishui, Huangmei, Susong and Taihu. Bamboo Dian he made is as thin as sharp of Chinese chives. He can use colored bamboo strips to fabricate a lot of

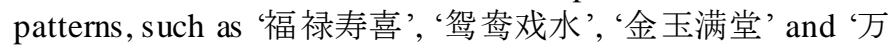
字格'. In the early years of the Republic of China, he took a hundred days and made two exquisite bamboo mats with double-side pattern. One side is the pattern of “二龙戏珠” and the other side is the pattern of “丹凤朝阳”. He sent to Panama International Expo for exhibition and won a prize.[6] After a century, Qichun and some southern regions still produce traditional bamboo mat. But there is no record about "Qi Dian".

In December 1974, relevant personnel in Qichun County confirmed a dragon-scale-shaped heterogenic bamboo as " $\mathrm{Q}$ bamboo", and listed it as the most important cultural plant. They erected a tablet to protect it. Later it was transplanted to Li Shizhen Cemetery in Qizhou. They redeemed it was Qi bamboo, one of our treasures in Qichun, for appreciation of visitors [7]. This kind of behavior can be understood. Among them, Qi wormwood can be found all over Qichun. Qi snake is near extinction. But we can still find it. Local people develop Qi turtle into an industry, and they succeed. Only Qi bamboo is completely vanished. In that age most of people seek quick success and instant benefits. Qi bamboo should have been found and protected. After more than 20 years, the image of "Qi bamboo" is quoted and related for many times [8]. In 1998, Wang Hongbin proposed to convoke a seminar upon Qi bamboo. They invited more than 40 experts and scholars in the county for discussion. You Run, expert of Nanhua Plant Garden, confirmed that the heterogenic bamboo at Li Shizhen Cemetery was dragon scale bamboo. After this, Wang Hongbin published Research and Development of Qi Bamboo and its Products on the 2nd issue of Guangdong Forest Industry Science in the year of 2000. He redeemed the historical Qi bamboo was Taozhi bamboo. In his another article, Research, Development and Inheritance of Qi Dian, he said the experts and scholars participating the seminar unanimously agreed on his view [9].

The author believes that there are many doubtful points in Mr. Wang's views. First, he was prejudiced by first impression. He firmly thought that Taozhi bamboo is Qi bamboo. He put the first thing last and the last thing first in his researches. Second, literatures and historical materials don't describe the shape of Qi bamboo, and only describe the characteristics of Taozhi bamboo. Third, the paper has stated that in Bamboo Manual, Jin · Dai Kaizhi recorded "Qi bamboo" was "Taozhi bamboo". However, this statement is not true for there is no such record. This book only recorded that Taozhi bamboo can be used to make bamboo mat, and people call it Tao Sheng. From the poem Qi Bamboo ·Four of Gu Jing xing, "Qi bamboo is able to make color Fengming. Minyun bamboo mat is superior to Tao Sheng", we can see the advantage and disadvantages of Qi Dian and Tao Sheng. Fourth, he quoted Li Kan's Details of Bamboo Manual for five times. For four times, he quoted "Taozhi bamboo has smoothed and yellow skin, and it can be made of mat. Now people call it Qi bamboo". "Qi bamboo formerly is called Tao zhi bamboo. Its joint is about 66 $\mathrm{cm}$ long. Its skin is smooth and yellow. It grows thickly and looks like sinocalamus affinis". "Qi bamboo grows thickly, and it looks like sinocalamus affinis" [10]. However, Li Kan wrote "only record what I know and wait for someone who knows" [11]. It shows he was also not sure about it. 


\section{CONCLUSION}

In fact, it has no meaning for the development and fabrication of Qi Dian to research Qi bamboo. The preceding part of the text has mentioned it. Since the end of Qing Dynasty, mat craftsmen in Qizhou had began to use other materials to make Qi Dian. Nowadays, mat craftsmen use Taozhi bamboo to make bamboo mat in Qichun. They also call it "Qi Dian". From 1997, Wang Hongbin visited all bamboo strip craftsmen in Qichun. He invested and cooperated with Gong Zhengguo, craftsman from Yangshufan Village, Caohe Town, and made 12 "Qi Dian". They have made a detail record and research on the craftsmanship [12]. It fully reflects the research value and meaning of Qi Dian. In addition, Mr. Wang also explained the healthy function of "Qi Dian". Han Yu wrote "Qizhou is famous for bamboo flute... all illnesses are cured after sleeping soundly". Then made it into "Qi Dian" and gave to his friend. "Patients who have wind-heat and rheumatism resulting in spasm and skin itch are miraculously cured after using Qi Dian". "Bamboo has a high medical value. Bamboo leaf, bamboo shavings, tabasheer and bamboo juice can be used as medicine. They all can relieve cough and reduce sputum" [13]. It is undoubted that the description of Han Yu is artistically exaggerated. Therefore, the healthy function of Qi Dian described by Mr. Wang is a little bit exaggerated. It seems to be a product of geographical indication. In the development process, modern marketing method goes against the value system, which, on contrary, is unfavorable to product research and development. We should rationally view the function of Qi Dian, care product craftsmanship and quality, and dig its cultural added value in order to meet people's need and give Qi Dian a development.

\section{REFERENCES}

[1] (Ming Dynasty of Jiajing Emperor) Qizhou Records. Qichun Chorography - Office Reprint. 2009: 95.

[2] Chen Yuanfa. Four Treasures in Qizhou. Sichuan Cultural Relics. 1988 (2), 64-65.

[3] Records of Qichun County. Hubei Science and Technology Press. 1997: 8.

[4] (Period of Jiajing Emperor) Huguang Tujing Zhi. Bibliography Record Press, 1991. (Volume IV of Huangzhou · Shanchuan · Qizhou)

[5] (In the Qing Dynasty of Guangxu Emperor) Qizhou Records. Qichun Chorography - Office Reprint. 2009: 134.

[6] Records of Qichun County. Hubei Science and Technology Press.1997: 871-872.

[7] Wang Hongbin \& Wang Luping. Research and Development of Qi Bamboo and Bamboo Products. Guangdong Forestry Science and Technology. 2000, 16(2) 22-26.

[8] Chen Yuanfa. Four Treasures in Qizhou. Sichuan Cultural Relics. 1988(2), 64-65.

[9] Wang Hongbin. Research and Development of Qi Dian. Qichun Literat ure and History. 2008(21).

[10] Li Kan. Details of Bamboo Manual. Zhejiang People's Fine Arts Publishing House. 2013: 169, 170.

[11] Li Kan. Details of Bamboo Manual. Zhejiang People's Fine Arts Publishing House. 2013: 171

[12] Wang Hongbin. Research and Development of Qi Dian. Qichun Literat ure and History. 2008(21).

[13] Xie Haizhou \& Liu Congming. Four Specialty Medicines in Qichun. Journal of Traditional Chinese Medicine.1984 (10), 79-80. 